\title{
Imposto sobre vehiculos
}

Um dos ultimos pareceres do Professor Doutor Manoel

Pedro Villaboim 


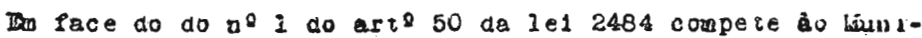
cipjo, entre outros,o jeposto.de licença dobre vehjculos.A Prefeltura lucal veno arsecaranao esse zuposto de sodos aquelles

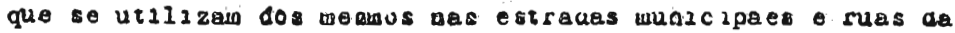
cldede, quer seja de lavrados ou nẽo. Elarseranto, ew folberze dz-

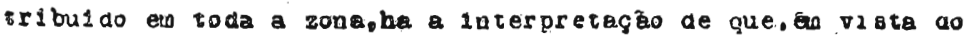
alsposto no arto 123, letra o da c1rada lelongo pode aquelle 1mposto recahir sobte o 12viacorglesce caso pergnta-se:

a) Pode o municipio cobredo isposto sobre vehiculos P

b)Está o latrador ou sitiante, oujelto a eoge lupoeto, upa vez trasitendo fota de ara proprieqaue?

c lo vehiculo de qualquer especie eswente empregado no arviço da ṕropria lavoure de que tala a lel ofganfopode crausicar fora da proprzeaseo, es estracras a ruas, sem pogar impostoz

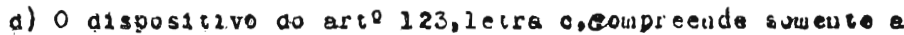
propriedace agricola, conforue eetabel ecerga lel eatacual para as nas iexas?

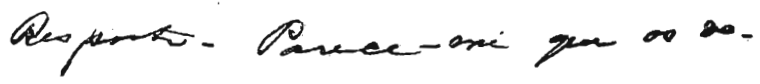

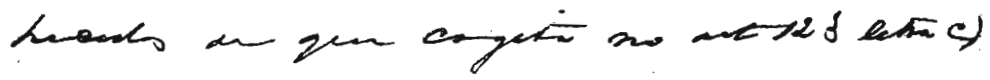

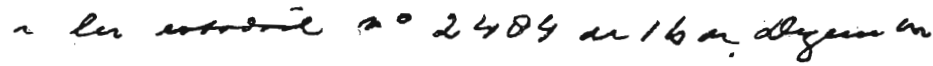

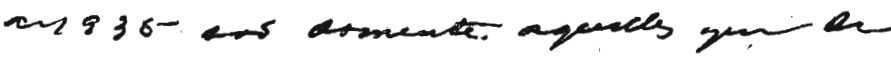

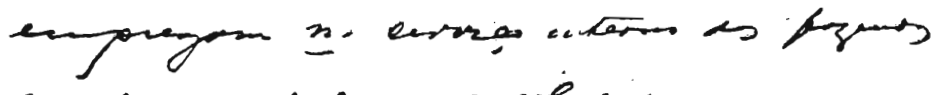

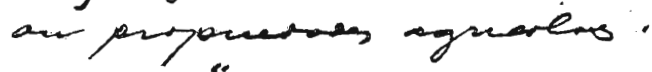

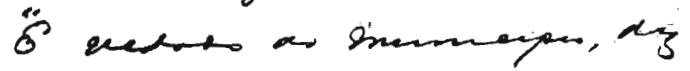

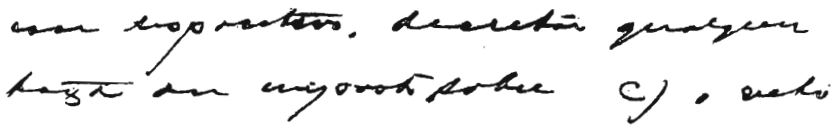

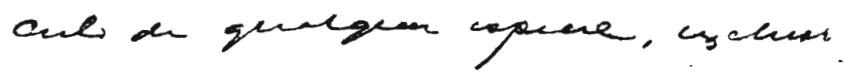

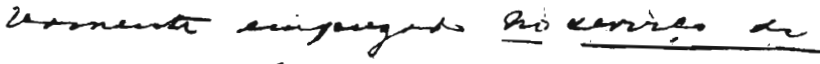

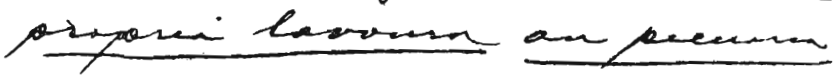




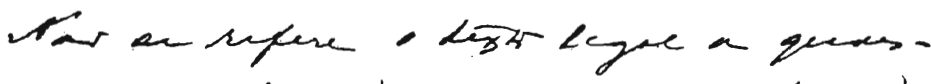

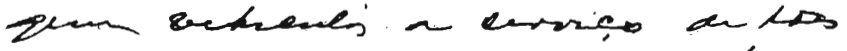
prppuciare, denta an forn de lesneter an to peranatso dicles,

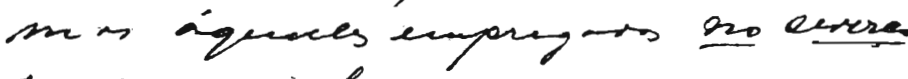

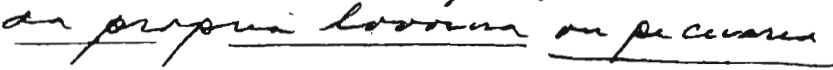

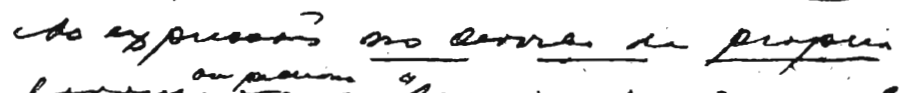

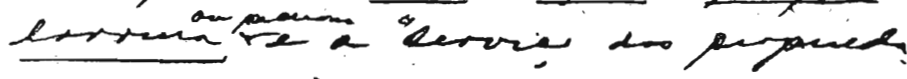

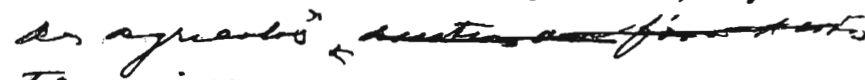

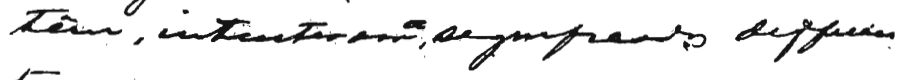

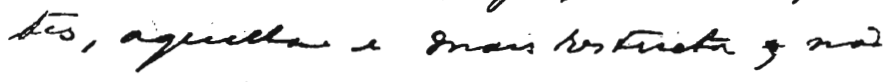

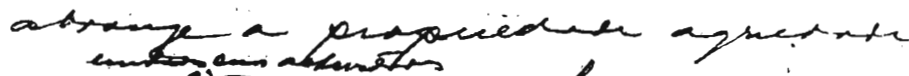

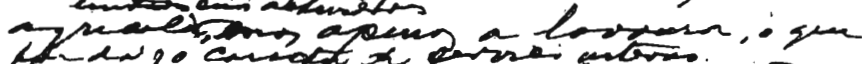

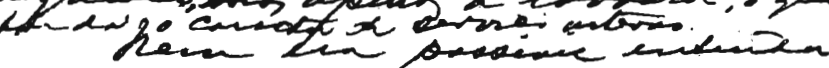

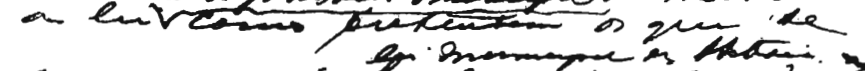

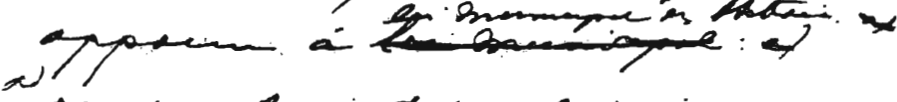

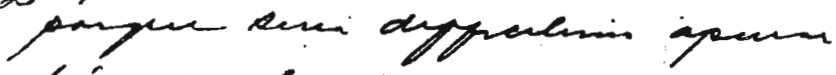

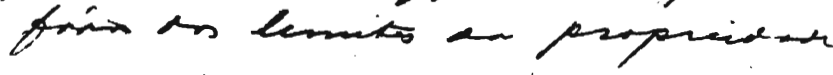

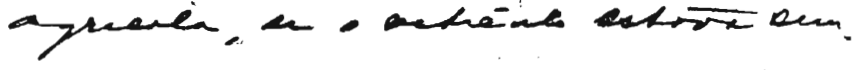

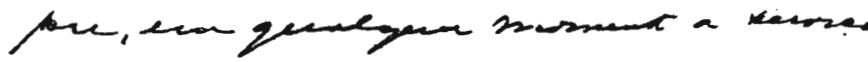

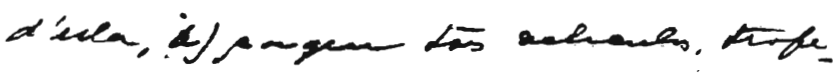

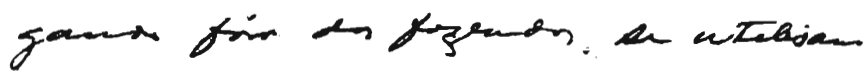

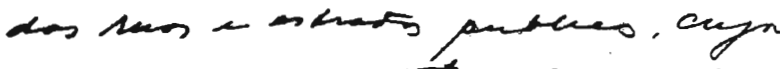

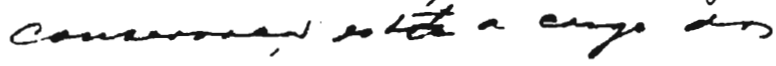

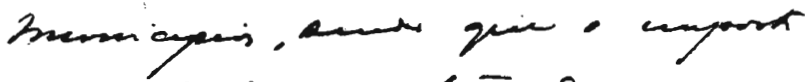

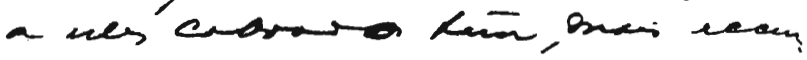

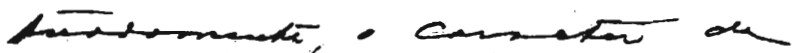

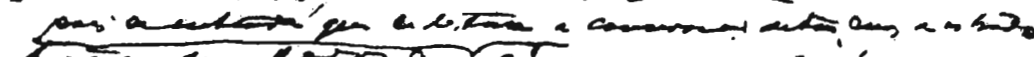

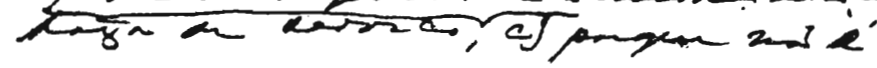


$-487-$

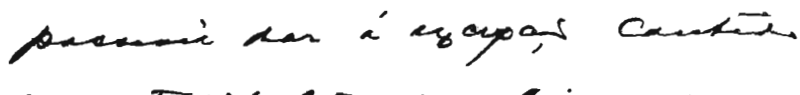
a weriz ex ejen $\mathrm{C}$.

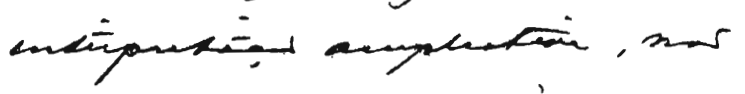
a'porpun os raposis enper

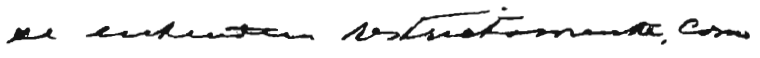

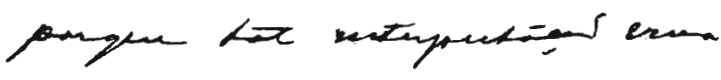

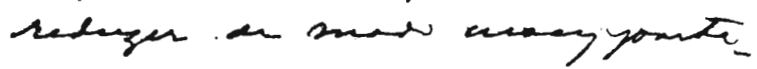
sed, cerne on fandis en seach

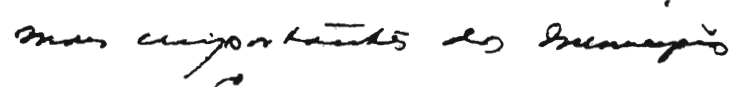

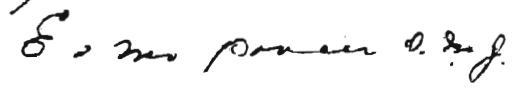

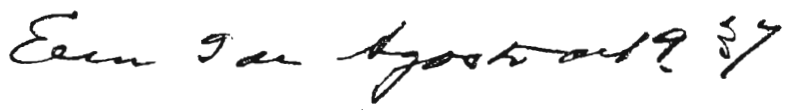

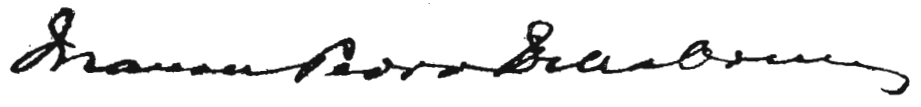

